Available online at GSC Online Press Directory

GSC Biological and Pharmaceutical Sciences

e-ISSN: 2581-3250, CODEN (USA): GBPSC2

Journal homepage: https://www.gsconlinepress.com/journals/gscbps

(CASE REPORT)

\title{
On a rare case of solitary fibrous tumor in a thyroid gland
}

\author{
Erra Stefania $1^{*}$, Zappaterra Giorgia ${ }^{1}$, Lancella Antonella ${ }^{2}$ and Berni Antonello ${ }^{2}$ \\ ${ }_{1}^{1}$ Surgical Pathology Department, Santo Spirito Hospital, Casale Monferrato, Italy. \\ 2 Department of Otolaryngology, Santo Spirito Hospital, Casale Monferrato, Italy.
}

Publication history: Received on 22 August 2018; revised on 10 September 2018; accepted on 20 September 2018

Article DOI: https://doi.org/10.30574/gscbps.2018.5.1.0091

\begin{abstract}
Solitary fibrous tumor (SFT) represents an ubiquitous soft tissue neoplasia, thought deriving from mesothelial cells. Most of cases are described in respiratory tract, even if many SFT have been reported in abdominal cavity, spermatic cord and some parenchymal organs, such as breast. Solitary fibrous tumor of the thyroid gland (T-SFT) is rarely described, with only 26 cases being reported since 2014 in the international literature [1]. In this manuscript we report a case of solitary fibrous tumor of the thyroid gland in a 67-years-old man occasionally detected on a thyroidectomy sample performed for other reasons.
\end{abstract}

Keywords: Solitary fibrous tumor; Thyroid gland; Mesothelial cells; Thyroidectomy

\section{Introduction}

SFT was initially described in the pleura but subsequently cases of this tumor have been reported in various localizations. The clinical course of this neoplastic entity is usually benign, but many aggressive cases have been documented both in pleura and in extrapleural sites.

SFT represents a rare nosological neoplastic lesion arising from mesenchymal cells of fibroblastic origin. It often arises primarily from the pleura, where SFT represents about 5\% of primary pleural tumors, while extrapleural occurrence are rare. In recent literature, SFT have been described in liver [2], in central nervous system, where 220 cases have been detected nowadays [3] and in bone [4]. In 2016, a unique case of giant SFT of the pleura metastasizing to the thyroid gland was described [5].

On morphological viewpoint, SFT is a spindle cell tumor, mimicking similar other entities of fibroblastic origin. Differential diagnosis needs immunohistochemical positivity detection for CD34 antibody.

Recently, a NAB2-STAT6 gene fusion has been identified as a consistent finding in SFT. This genetic fusion results in a chimeric protein in which a repressor domain of an EGR1 binding protein 2 is replaced with a transactivation domain from signal transducer and activator of transcription 6, interleukin-4 induced (STAT6). Detection of nuclear expression of the carboxy-terminal part of STAT6 is reliable in differential diagnosis of SFT [6]. Antibodies against the STAT6terminal can be used to identifying the gene which is considered a specific molecular marker for solitary fibrous tumor. In fact, a recent study showed a diffuse and strong nuclear STAT6 expression only in solitary fibrous tumor, while other neoplastic lesions were negative or showed only weak cytoplasmic expression [7].

\footnotetext{
${ }^{*}$ Corresponding author

E-mail address: stefania.erra@virgilio.it
} 


\section{Case report}

In this paper, it has reported a case of a 67 years old smoker and drinker man, with a complex pathological and longdate history. He was suffering from chronic bronchitis, hypertension, and severe damage of the arteries in the lower limbs. He was subjected to right femoral popliteal bypass and amputation of the left leg. Three months ago a CT exam revealed an enlarged lymph node of the neck and a partially cystic nodule of the left thyroid lobe, $4 \mathrm{~cm}$ in size. This nodule deviated and compressed the trachea, without restricting its lumen, partially engaging in the mediastinum.

Fine needle aspiration cytology (FNAC) was performed $\times$ on pathologic lymph node and on thyroid nodule. The first resulted a metastatic localization of squamous carcinoma, while thyroid FNAC was not diagnostic for the absence of thyrocytes.

Total thyroidectomy was performed, with cervical node dissection. Specimens were send to surgical pathology department for histological evaluation. Pathologic nodes were positive for squamous cell carcinoma from pharynx, confirmed by magnetic resonance of head and neck. The macroscopic examination of the thyroid gland confirmed the presence of a blind-looking nodule almost completely occupying the left lobe (figure 1).

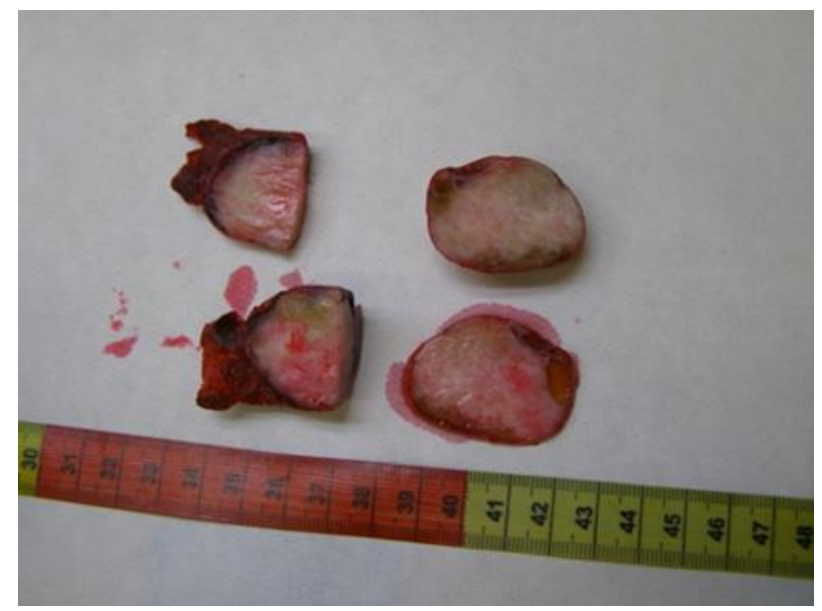

Figure 1 Thyroid nodule aspect after fixation

On microscopic evaluation, a firm, whitish and capsulated nodule presented. It was composed of spindle and monomorphic cells intermingled with thyroid follicle, with abundant collagen deposition (figure 2).

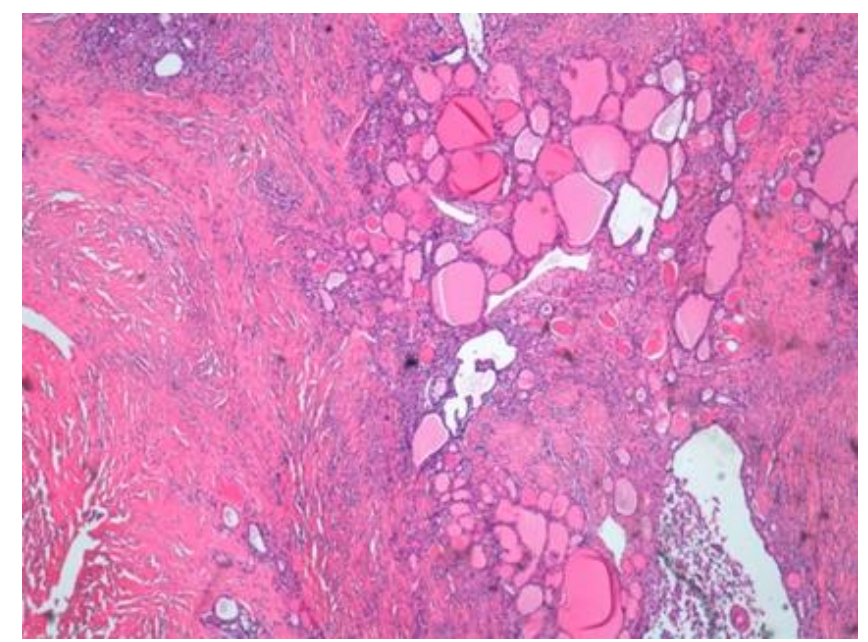

Figure 2 Microscopic observation of thyroid nodule 
The immunophenotype of the neoplastic elements presented a strong positivity for CD34 (figure 3), bcl-2 and CD99, confirming the first diagnostic hypothesis of solitary fibrous tumor.

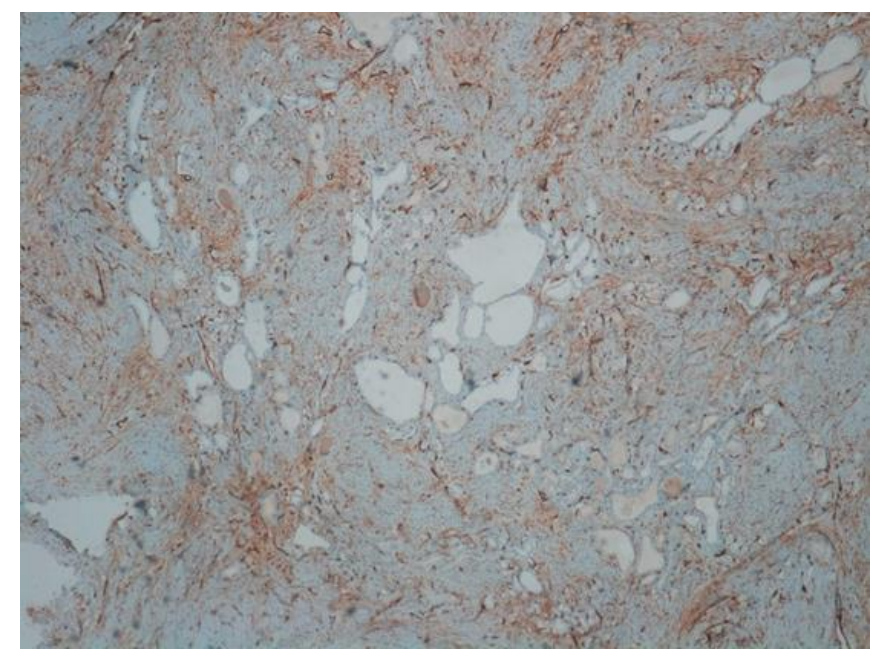

Figure 3 CD34 positivity of neoplastic cells

\section{Discussion}

Solitary fibrous tumor is a rare spindle-cell neoplasm, which was reported for the first time by Klemperer and Rabin in 1931 as a pleural primitive malignancy [8]. For its microscopic appearance, this pathologic entity was thought originating from perivascular structure, so many described cases were been reported as haemangiopericytoma in past. Nowadays, the use of this last term is discouraged because putting in confusion. In fact branching vascular structures observed in solitary fibrous tumor are common in many other neoplasia. Histologically, SFT has a wide range of features, ranging from high cellular lesions to hypocellular and quite fibrous one. What all the SFT have in common are the type of cells and the tendency to be well-circumscribed lesions. Generally the cell of SFT is spindle with rounded or fused nuclei with vesicular chromatin, few mitotic figures and rare necrotic areas. Characteristically, in SFT blood vessels are numerous and rounded formed, sometimes with thickened walls. On immunohistochemistry tumor cells are strongly positive for vimentin and CD34, CD99 and bcl-2.

In extra-pleural sites, SFT has been reported in retroperitoneum, deep soft tissues of limbs, abdominal cavity and neck. In this last anatomical region, SFT accounts for 10\% [9]. SFT arising in the thyroid is very rare. It often occurs in adult patients in an age range between 28 to 76 years old. Nowadays 26 cases have been described in literature, with a male prevalence and quite benign clinical course [10-12]. All the mentioned thyroid SFT appear as a solid and wellcircumscribed mass, similar to the case observed in our patient. This type of neoplastic lesion may have benign or malignant variants but there are no distinct pathologic criteria to define biological course of this nosological entity. In the 26 cases of thyroid SFT only one gave pulmonary metastases [5].

In the molecular era, genetic alterations have been searched in SFT, without common characteristic features [13], with several translocations and chromosomal aberrations. Only in recent years, it has been detected NAB2-STAT6 fusion chimeric gene, even if the molecular determinants of malignancy is unknown [6]. In 2016, Bahrami and others published an article with the proposal to detect telomerase reverse transcriptase (TERT) reactivation induced by promoter mutations as a potential molecular mechanism for aggressive clinical behavior in solitary fibrous tumors [14]. In their retrospective study on 96 SFT coming from numerous pathologic structures, patients with TERT promoter mutations had a significantly poorer event-free survival than those with the wild-type TERT promoter.

\section{Conclusion}

Finally, even if it isn't possible to predict the clinical and biological course of the lesion reported in our patient, the morphological characteristics and the immunohistochemistry study confirm that thyroid nodule is consistent with a solitary fibrous tumor. In light of numerous clinical morbidity of this patient, we think that SFT detected in his thyroid could have aggressive biological tendency. Nowadays, there isn't possibilities to investigate on molecular levels all the SFT diagnosed, because genetic determinations can be done in very few laboratories only. For this reason, it becomes 
important to have a high panel of antibodies detecting molecular aberrations or chimeric protein on immunohistochemical method. In SFT, STAT-6 antibody has an important role in differential diagnosis, above all in controversial cases. In the reported tumor, there hasn't been diagnostic problems, because the lesion was positive for CD34 and bcl2 antibodies on immunohistochemistry. Instead, the possibility to investigate reliable prognostic factors with immunohistochemistry method could affect the clinical and therapeutic behavior and follow-up steps of our patient.

\section{Compliance with ethical standards}

\section{Acknowledgments}

None

\section{Disclosure of conflict of interest}

Authors declare that there are no conflicts of interest in connection with this paper, and the material described is not under publication or consideration for publication elsewhere.

\section{Statement of informed consent}

Informed consent was obtained from the patient included in the study.

\section{References}

[1] Verdi D, Pennelli G, Pelizzo MR and Toniato A. (2016). Solitary fibrous tumor of the thyroid gland: a report of two cases with an analysis of their clinical and pathological features. Endocrine pathology, 22(3), 165.

[2] Shinde RS, Gupta A, Goel M, Patkar S. (2018). Solitary fibrous tumor of the liver-An unusual entity: A case report and review of literature. Annals of hepato-biliary-pancreatic surgery, 22(2), 156-158.

[3] Rana N, Kim E, Jaboin JJ and Attia A. (2017). The Role of Adjuvant Radiation in the Management of Solitary Fibrous Tumors of the Central Nervous System. International Journal of Radiation Oncology• Biology• Physics, 99(2), E102.

[4] Suarez-Zamora DA, Rodriguez-Urrego PA, Soto-Montoya C, Rivero-Rapalino 0 and Palau-Lazaro MA. (2018). Malignant Solitary Fibrous Tumor of the Humerus: A Case Report of an Extremely Rare Primary Bone Tumor. International journal of surgical pathology.

[5] Ning S, Song X, Xiang L, Chen Y, Cheng Y and Chen H. (2011). Malignant solitary fibrous tumor of the thyroid gland: report of a case and review of the literature. Diagnostic cytopathology, 39(9), 694-699.

[6] Doyle LA, Vivero M, Fletcher CD, Mertens F, Hornick JL. (2014). Nuclear expression of STAT6 distinguishes solitary fibrous tumor from histologic mimics. Modern Pathology, 27(3), 390.

[7] Magro G, Spadola S, Motta F, Palazzo J, Catalano F, Vecchio GM and Salvatorelli L. (2018). STAT6 expression in spindle cell lesions of the breast: An immunohistochemical study of 48 cases. Pathology-Research and Practice.

[8] Klemperer P and Rabin CB. (1992). Primary neoplasms of the pleura. A report of five cases. American journal of industrial medicine, 22(1), 4-31.

[9] Hornick JL. (2013). Practical soft tissue tumor, a diagnostic approach. Elsevier saunders, ISBN 978-I-4160-54559.

[10] Mizuuchi Y, Yamamoto H, Nakamura K, Shirahane K, Souzaki M, Tanaka M and Oda Y. (2014). Solitary fibrous tumor of the thyroid gland. Medical molecular morphology, 47(2), 117-122.

[11] Alves Filho W, Mahmoud RR, Ramos DM, Araujo-Filho VJ, Lima PP, Cernea CR and Brandão LG. (2014). Malignant solitary fibrous tumor of the thyroid: a case-report and review of the literature. Arquivos Brasileiros de Endocrinologia and Metabologia, 58(4), 402-406.

[12] Zhigang S, Chunkai Y, Xin S, Lixin W and Aijun L. (2011). Primary Solitary Fibrous Tumor of the Thyroid - Report of case and Review of the Literature. Journal of Cancer, 2, 206-209.

[13] Torabi A, Lele SM, DiMaio D, Pinnt JC, Hess MM, Nelson M, Bridge JA. (2008). Lack of a common or characteristic cytogenetic anomaly in solitary fibrous tumor. Cancer genetics and cytogenetics, 181(1), 60-64. 
[14] Bahrami A, Lee S, Schaefer IM, Boland JM, Patton KT, Pounds S and Fletcher CD. (2016). TERT promoter mutations and prognosis in solitary fibrous tumor. Modern Pathology, 29(12), 1511.

\section{How to cite this article}

Erra S, Zappaterra G, Lancella A and Berni A. (2018). On a rare case of solitary fibrous tumor in a thyroid gland. GSC Biological and Pharmaceutical Sciences, 5(1), 21-25. 